\title{
THE IMPACT OF INVENTORY CONTROL PRACTICES ON COST REDUCTION: THE CASE OF LEBANESE RETAIL COMPANIES
}

\author{
Denis Ushakov \\ South-Russian Institute of Management, Russia Presidential Academy of National Economy and Public \\ Administration, Rostov-on-Don, Russia
}

Khodor Shatila

iProcares research center, Beirut, Lebanon

Inventory is a significant aspect in administration of items and services or other commodities that are kept in storage by companies and organizations. The research deals with four research variables which are vendor management inventory, lean practices, inventory management and strategic supplier management in their relation to the performance of retail companies. The research is based on the use of the mixed study approach, which aims at defining the effects of inventory control on cost reduction and operational performance of retail firms in Lebanon. The research addressed 123 respondents from the two companies. Also, the researcher has carried out six interviews with three managers from each of these two companies. The data was collected using Google forms, and then analyzed using SPSS. Descriptive analysis, inferential statistics and normality distributions were used to analyze the collected data, and the research has found a direct relationship between vendor inventory management, inventory stock taking, lean practices and strategic supplier relationships and the operational performance of the companies in question. The research recommended three new models to be implemented in further studies, and these models include the independent variables as a dependent variable.
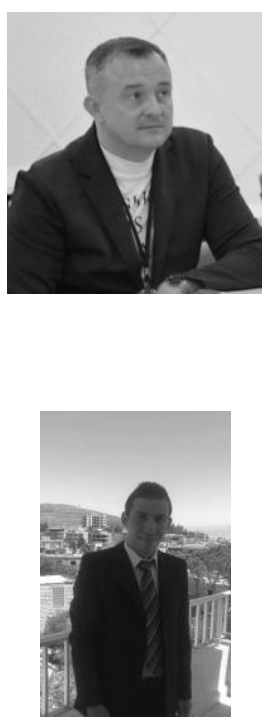

\section{Denis Ushakov}

Dr. of economy, Professor, South-Russian Institute of Management, Russia Presidential Academy of National Economy and Public Administration, Rostov-on-Don, Russia.

Research interests: tourism industry, multinational business, international service markets, migration. Published more than 200 research papers included 15 students' manuals and 80 papers in internationally indexed journals.

E-mail: fintaliano@yandex.ru

\section{Khodor Shatila}

Masters' in Business Administration, Sagesse University, Furn El Chebbak Baabda, Lebanon. Researcher in iProcares international research center, Beirut, Lebanon.

Research interests: international logistic, transnational supply chains, human resources management, multinational management. Published more than 5 papers in internationally indexed journals, participated in 4 international conferences.

E-mail: info1@iprocares.com 
Keywords: inventory management; lean practices; strategic supplier relationships; operational performance; inventory stock

\section{Background}

Inventory has become by now a significant aspect in management of items, services and other commodities. An inventory system consists of a set of policies and controls which monitor inventory levels and determine which levels should be kept, when stocks should be filled up and how large orders should be processed (Vipulesh, 2015).

Inventory control needs the required amounts of inventory to sustain everyday activities of the company at minimal expenses. This includes purchasing stock, its reception and testing, availability of adequate storage facilities and more.

\section{Empirical Review}

\section{Inventory Control and Organizational Profitability}

Agu (2016) indicated that excess inventory could lead to incurring inventory costs and losses in inventory storage location, and also leads to liability in product activities. Ordering raw materials is a significant element that directly affects production costs. At the same time, limited volumes of ordering raw materials are known to be an efficient SME technique.

To gather data from participants, a concise research design was created. The quantitative methodology has been chosen because it can give the researcher a comprehensive profile and quickly explain the specific features of stock management activities.

The study's focus population is 400 suppliers from Central Business Districts in Nairobi (Kenya). However, 350 respondents did not return the questionnaires for various reasons. The obtained data has been evaluated in SPSS.

Our objective here has been to validate the following hypothesis:

H1: There is a direct positive relationship between inventory control and organizational profitability.

Vendor Management Inventory Systems and Organizational Profitability

Empirical researches on VMI were conducted, inter alia, by Heese (2015) using qualitative methodology.

The key research question posed in the VMI methodological studies usually concerns the effect of VMI on operational performance.

Lundu \& Shale (2015) also mentioned that without applying VMI, the advantages of their model could have been recognized through the growth of the buyer's ordering.

Thus, many research studies have already suggested that VMI has a beneficial impact on the performance of supply chains. Suppliers may not immediately profit from it though, but other benefits from the VMI model may not be obtainable without the supplier's decisions-making in this regard.

This leads us to the following hypothesis:

H2: There is a direct positive relationship between vendor management inventory and organizational performance. 


\section{THE IMPACT OF INVENTORY CONTROL PRACTICES}

\section{Inventory Management and Profitability}

As described by (Ruth, 2012), the inventory management method is a mechanism where an organization financially deals with the criteria to be reached by controlling stocks. The business stock levels will be kept at the maximum rates to minimize costs and boost its efficiency, a core aim of the stock management program as such.

Bad inventory management may contribute to the uncertainty. Work-in-progress buffers discourages employees, leads to their absenteeism and system breakdowns, whereas output defects and unexpected demand may be observed in part of finished products.

Thorsen \& Yao (2017) noted that inventory acts like an insurance fund to prevent accidental breakdowns and all other delays in operations. Overstocking, weak relationships with suppliers and inadequate usage of IT are only several of those factors that may minimize inventory control, thus affecting the efficiency of the procurement method, according to the report.

Patil \& Divekar (2014) emphasized that the value of stock is dependent upon different elements and aspects. A strong inventory control program is essential as it helps with stock fluctuations prevention, excess, degradation, obsolescence and high costs of transportation through better procurement decision-taking in the organization.

For an organization which expects its procurement role to be efficient and deliver quality services, strategic alliances and an inventory management program as well as successful use of IT are essential.

This leads us to the following hypothesis:

H3: There is a direct and positive relationship between inventory management and organizational profitability.

\section{Strategic Supplier Relationship Practices and Organizational Profitability}

The supply chain management includes long-term \& short-term goals. The long-term targets include value-for-money development for consumers, sales growth, improved productivity in market share (Ogbo \& Ukpere, 2014).

Lundu (2015) also suggested that efficiency, performance and sensitivity criteria of vendors in lean environments should be fulfilled. Their research found out that consumers consider it impossible to satisfy these criteria except for lean approaches followed by retailers themselves. This argument was one of the main issues relevant to shifting stocks from a buyer's firm to its suppliers in the just-in-time (JIT) setting.

This would decrease stock and related expenses in the buying business while growing inventory and expenses in the supply sector. This author concluded that successful product incorporation is a major factor in preserving the productivity of plants. The co-operating partnership with suppliers, including: confidence, helping suppliers to enhance their operations, knowledge exchange, the participation of suppliers in innovative product growth, and long-term ties, may also boost efficiency and competitive advantage.

This leads us to the following hypothesis:

H4: There is a direct and positive relationship between strategic supplier relationship management and organizational profitability. 


\section{Methodology}

\section{Data Collection}

In order to gather data from the interviewees who could interpret and write and address the queries, both primary and secondary data were gathered and organized using semistructured questionnaires and also through using interviews. The answers were constructed based on the Likert Scale which includes Strongly Agree (1), Agree (2), Neutral (3), Disagree (4), \& Strongly Disagree (5). Each variable in the research has a set of questions to measure it in order to maintain validity and reliability.

The analysis of qualitative and quantitative data has been carried out. Qualitative data has been analyzed using NVIVO software and quantitative data - using SPSS.

The survey was conducted with the help of Google forms, distributed to the predefined number of respondents. Then, the collected data was analyzed using SPSS.

\section{Study population and sample size}

The research covers the workforce engaged in inventory control and cost reduction in the addressed companies. The population of the research includes around 1000 employees of the retail companies which the research is addressing.

The research settings include a confidence interval of $95 \%$, a margin error of $5 \%$ and a population proportion of $50 \%$. After making the desired calculations, the approximate number of the respondents that should be addressed through the survey has been 123 respondents.

As for the interviews, three managers from each company were approached for the interviews. Their responses were then analyzed in detail.

\section{Regression Analysis}

The findings reveal that all four retail chain output variables (R) were collectively associated with the 0.605 value. This indicates that inventory management activities are growing (the inventory system, lean practices, inventory stock taking and strategic supplier management), thus having a positive and strong effect on performance.

The findings also present the coefficient of determination (R-square) which captures a percentage change in the performance of retail chains attributed to inventory control practices that is VMI Inventory System, Lean Practices, Inventory Stock Taking and Strategic Supplier Management.

The value of R-square is 0.565 which reveals that inventory control practices account for up to $56.5 \%$ of the variations in performance.

It can be thus concluded that there is at least one more factor (probably more than one) that has a direct impact on inventory control practices within the studied companies. 


\section{THE IMPACT OF INVENTORY CONTROL PRACTICES}

Table 1 - Results of regression analyze (made by the authors)

\begin{tabular}{|c|c|c|c|c|c|c|c|c|}
\hline \multicolumn{6}{|c|}{ Model Summary } & & & \\
\hline \multicolumn{2}{|c|}{ Model } & $\mathrm{R}$ & $\begin{array}{c}\mathrm{R} \\
\text { Squre }\end{array}$ & Adjusted R & $\begin{array}{l}\text { Std. Error of the } \\
\text { Estimate }\end{array}$ & & & \\
\hline \multicolumn{2}{|r|}{1} & $.605^{\mathrm{a}}$ & .565 & .338 & .04962 & & & \\
\hline \multicolumn{9}{|c|}{$\begin{array}{l}\text { a. Predictors: (Constant), Vendor Management Inventory, Strategic Management, } \\
\text { Lean Practice, Inventory Stock Taking }\end{array}$} \\
\hline \multicolumn{9}{|c|}{ Coefficients } \\
\hline \multirow{2}{*}{\multicolumn{2}{|c|}{ Model }} & & & \multicolumn{2}{|c|}{$\begin{array}{l}\text { Unstandardized } \\
\text { Coefficients }\end{array}$} & $\begin{array}{l}\text { Standardized } \\
\text { Coefficients }\end{array}$ & \multirow[t]{2}{*}{$\mathrm{t}$} & \multirow[t]{2}{*}{ Sig. } \\
\hline & & & & $\mathrm{B}$ & Std. Error & Beta & & \\
\hline \multirow{5}{*}{1} & \multicolumn{3}{|c|}{ (Constant) } & .101 & .023 & & 4.357 & .050 \\
\hline & \multicolumn{3}{|c|}{ Strategic Management } & .748 & .119 & .708 & 6.305 & .001 \\
\hline & \multicolumn{3}{|c|}{ Inventory Stock Taking } & .236 & .102 & .269 & 2.311 & .023 \\
\hline & \multicolumn{3}{|c|}{ Lean Practices } & .012 & .005 & .253 & 2.726 & .008 \\
\hline & \multicolumn{3}{|c|}{ Vendor Management Inventory } & .010 & .005 & .181 & 2.007 & .048 \\
\hline
\end{tabular}

The regression coefficient findings reveal a constant value of 0.050 which indicates that the predicted performance of retail chains when inventory control practices are zero or absent. This means that without inventory control practices the performance would be much worse. This corresponds to the results obtained earlier by (Mbula et al., 2016), who indicated that lack of or inadequate inventory management practices leads either to stockpiling or stocks, which in turn negatively affects a retail company's overall performance.

The findings indicate a favorable and substantive association between VMI systems and retail chain market success $(B=0.181$, Sig $=0.048,<0.05)$.

The findings also show a positive and significant relationship between lean practices and performance $(\mathrm{B}=0.253$, Sig $=0.008,<0.05)$. A 0.253 unit increase in performance if lean practices are increased by 1 .

The regression results also show a good and substantial relationship between inventory taking and retail chain business performance $(\mathrm{B}=0.269, \mathrm{Sig}=0.023,<0.05)$. This finding indicates that when stock stocks are increased by 1 unit, the performance of retail chain stores is increased by 0,269 units.

Finally, the results show that the link between strategic supply management and performance is positive and significant $(B=0.708$, Sign $=0.001,<0.05)$. This results in higher efficiency of 0.708 units, in case the strategic supply management goes up by $1 \%$.

\section{Pearson Correlations}

The results indicate that the efficiency of the influence of the vendor control inventory framework (Pearson Coefficient $=.230, \mathrm{Sig}=.020,<0.05$ ) is positive and significant. This means that an improvement in the inventory system of vendor management leads to an increase in retail chain operations.

Moreover, it has been shown that lean methods have a favorable and important impact on the efficiency of supermarket chain stores (Pearson Coefficient $=.219$, Sig $=0.027$, < $0.05)$.

This means that improved lean practices will lead to performance improvement. The study has also tested how technology and innovation are implemented in time. Using 
quantitative modeling they found that lean practices implementation results in company's efficiency growth in the long term.

There are also results showing a favorable and important effect of product on efficiency (Pearson Coefficient $=.237, \mathrm{SIG}=0.017,<0.05)$. This means that increasing product inventory levels contributes to efficiency changes.

The results further revealed that performance is positively and significantly affected by strategic supplier management practice (Pearson Coefficient $=.499, \mathrm{Sig}=0.000,<0.05$ ). This includes developing proactive supply procurement processes contributing to efficiency enhancement.

Table 1 - Results of Pearson correlation (made by the authors)

\begin{tabular}{|c|c|c|c|c|c|c|}
\hline & & $\begin{array}{c}\text { Vendor } \\
\text { Management } \\
\text { Inventory }\end{array}$ & $\begin{array}{c}\text { Lean } \\
\text { Practices }\end{array}$ & $\begin{array}{l}\text { Operational } \\
\text { Performan- } \\
\text { ce } \\
\end{array}$ & $\begin{array}{c}\text { Strategic } \\
\text { Manage- } \\
\text { ment }\end{array}$ & $\begin{array}{c}\text { Inventory } \\
\text { Stock } \\
\text { Taking } \\
\end{array}$ \\
\hline \multirow{3}{*}{$\begin{array}{c}\text { Vendor } \\
\text { Management } \\
\text { Inventory }\end{array}$} & Pearson Correlation & 1 & $.681 * *$ & $.230 *$ & $.451 * *$ & $.621 * *$ \\
\hline & Sig. (2-tailed) & & .000 & .020 & .000 & .000 \\
\hline & $\mathrm{N}$ & 123 & 123 & 123 & 123 & 123 \\
\hline \multirow{3}{*}{$\begin{array}{c}\text { Lean } \\
\text { Practices }\end{array}$} & Pearson Correlation & $.681 * *$ & 1 & $.219 *$ & $.448 * *$ & $.584 * *$ \\
\hline & Sig. (2-tailed) & .000 & & .027 & .000 & .000 \\
\hline & $\mathrm{N}$ & 123 & 123 & 123 & 123 & 123 \\
\hline \multirow{3}{*}{$\begin{array}{l}\text { Operational } \\
\text { Performance }\end{array}$} & Pearson Correlation & $.230 *$ & $.219 *$ & 1 & $.499 * *$ & $.237 *$ \\
\hline & Sig. (2-tailed) & .020 & .027 & & .000 & .017 \\
\hline & $\mathrm{N}$ & 123 & 123 & 123 & 123 & 123 \\
\hline \multirow{3}{*}{$\begin{array}{c}\text { Strategic } \\
\text { Management }\end{array}$} & Pearson Correlation & $.451 * *$ & $.448 * *$ & $.499 * *$ & 1 & $.665 * *$ \\
\hline & Sig. (2-tailed) & .000 & .000 & .000 & & .000 \\
\hline & $\mathrm{N}$ & 123 & 123 & 123 & 123 & 123 \\
\hline \multirow{3}{*}{$\begin{array}{c}\text { Inventory } \\
\text { Stock Taking }\end{array}$} & Pearson Correlation & $.621 * *$ & $.584 * *$ & $.237 *$ & $.665 * *$ & 1 \\
\hline & Sig. (2-tailed) & .000 & .000 & .017 & .000 & \\
\hline & $\mathrm{N}$ & 123 & 123 & 123 & 123 & 123 \\
\hline
\end{tabular}

\section{Interviews with Managers in Retail Company X}

\section{Interview One}

The first interview was organized with the cost controller in the addressed retail company, and he stated that two of the most common problems that the company is facing are inefficient communication and incomplete access.

Like many other issues, inventory management issues often begin with mere misunderstandings. It is incredibly challenging for the staff to build workflows that would help the distribution program if they don't have a real-time link to critically important details.

One cannot build positions and hierarchies to sustain such workflows without good communication. Authorizations, updates and changes in policy can be delayed or even lost.

Thus, sales staff, communications departments and (most importantly) consumers cannot obtain valuable details regarding the goods being sold when the e-commerce inventories are not correctly synced. Financial reports, forecasts and monitoring would therefore be jeopardized because the involved employees would have little evidence to forecast and prepare for the future. 


\section{THE IMPACT OF INVENTORY CONTROL PRACTICES}

\section{Interview Two}

The second interview was conducted with a warehouse manager in the addressed retail company, and he stated that the main issue the company is facing is the absence of warehouse management.

Larger warehouses that are complex physically may trigger considerable damages and losses if they are inadequately controlled.

Manual collection of all data coupled with the absence of a centralized data management strategy may lead to the following negative situations:

Forgotten orders;

Incorrect counts in inventory;

Barcodes and unit of inventory (SKU) numbers being inaccurate or duplicated;

Slow processing of orders;

Flaws in delivery;

Returns are inaccurate or unfulfilled;

No connection between orders, shipping papers, and submitted invoices;

Having an excess inventory means high storage costs and less room for more successful products.

Also, there may be problems with significant quantity of "dead stock", or less common, not inherently spoiled, but simply lost, but clearly not in demand products. Storage space and resources should be better saved and used for more demand-driven housing products, like the over-stock of current products.

Due to this lack of centralized data management and poor communication, inventory discrepancies can also occur in multiple locations, creating an exponentially costly disaster.

\section{Interview Three}

The third interview was conducted with an inventory control manager, and the main problem that the company is facing, in his opinion, is overselling and stock shortage.

This problem is actually the opposite to store surplus stocks: the inventory does not satisfy consumer demand. Both issues arise from the same sources - poor communication, poor analysis, and incomplete monitoring of inventory. It is also quite easy to make a mistake concerning the current market trends without having full control into the supply chain and secure access to common data services.

Oversale is a result of inaccuracies in the so-called defense stocks, the total amount of articles that would be sufficient to satisfy the expected demand. Since the prices for each commodity may differ with the market patterns and changing consumer preferences, access to relevant data and its further analysis would help with making inventory more reliable and effective.

\section{Main Findings}

A range of variables may affect the implementation of a particular inventory management technique or combination of such techniques (IMTs). The findings of our research here suggest that these methods may differ depending on a company's size. Also, the following deciding considerations have been reported in the earlier literature in this regard: large businesses will likely have more inventories and thus, would enjoy more benefits of utilizing warehouses as compared to smaller companies. 


\section{Findings Regarding Vendor Managed Inventory}

VMI is a coordinated supply chain system in which vendor takes over stock management. The seller manages the stocks on the basis of consumer order information. The key distinction of VMI as a system is that the seller has the duty over stock prices as compared to the traditional retailer controlled inventory.

The title to the goods in some variations of VMI will not be changed to the supplier until the goods are consumed and some of the stock managed by the vendor.

The retailer has a real VMI setting as long as the accepted customer care requirements are followed, to prepare his own development and determine the reclassification schedules. VMI can be implemented at both minimum and maximum inventory levels, and the supplier is responsible for maintaining the inventory levels.

\section{Findings Regarding Inventory Stock Taking}

As a rule, leaner businesses are seeing higher returns than the market average. As a test of assets control, they use an objective leanness metric. Contrary to this study, the focus of their work is to evaluate the relationship between inventory performance and overall company performance. The drawback of this principle is that it can only be true if a corporation and its trade partners collaborate strongly and in a long-term manner, and exchange new knowledge on a regular basis.

Inventory management performed according to the lean theory as an important component of a supply chain, regardless of whether the supply chain is for a product or a service. Inventory management plays a significant function in keeping demand and supply in line with each collaborator through the entire value chain and in the final review of external and internal developments within the unpredictable, globalized market world of today.

Ineffective inventory management is a big challenge since it is affecting businesses since to date only the most common principles and methods of inventory control are being applied by the majority of companies and organizations.

\section{Finding Regarding Supplier Strategic Management}

Supplier partnership includes all cooperation efforts enhancing the supplier's technology, quality, delivery time and cost capabilities. It also promotes all related ongoing improvements.

Our research indicates that the main aspects characterizing successful development of suppliers include: integration and improvement of activities and processes, ongoing cooperation and long-term relationships, mutual benefits as a consequence of the improvement efforts and an apparent structure in terms of costs, prices and profit for all parties involved.

The research has also shown that purchasing companies should treat suppliers as partners. It is claimed that participating in the activities normally considered to be the area of the other company would lead to reduced future risks in supplier relationships.

The research also demonstrates that such a partnership allows both parties to improve the decision-making process, increase the efficiency of knowledge exchange, promote communication and improve overall performance on both sides. The research shows that the purchasing company will benefit from the efforts to improve the supplier's performance, as both companies share the benefits from improved productivity. In addition, technological 


\section{THE IMPACT OF INVENTORY CONTROL PRACTICES}

support offered to suppliers helps them to provide products more regularly and just-in-time, thus increasing consistency, efficiency and product distribution.

\section{Theoretical Contributions and Managerial Implications}

The findings of this research contribute to the resource-based theory since every company depends on its supplies and resources when it comes to income and other benefits.

Furthermore, the study contributes to the lean theory, since it aims to reduce waste to the minimum. Lean inventory impacts firms' profitability and is regarded to be the most reliable storage tool. Our study illustrates how suppliers may reduce inventory levels and avoid the costs of shipping products.

Finally, our findings also contribute to the Economic Order Quantity (EOQ) Theory since the companies in question aim to reduce the expenses on goods; the economic order quantity can be described as the product costs. To illustrate the order and production costs incurred in the procurement of goods. In order for the business to prevent high maintenance expenses and reduces product losses, economic order quantity should be calculated. EOQ aims to reduce inventory costs, so prices for the products ordered can be recalculated.

\section{Further Research Recommendations}

Taking into account the proposals made in the previous section, we can put forward the following recommendations as per the initial study purposes: a sustainable shopping strategy if followed by the suppliers is able to deliver the best products at affordable prices. For the success of resource control the credibility of the buying sector plays an important role. The retail companies should ensure that the information on average buying efficiency and the level of competitiveness is open and transparent.

With the introduction of an integrated stock management system, all data may be exchanged among shopping divisions so that the latter may have a common view of what is happening in product storage and when is the right time to buy. The primary objective of inventory control is to define the cost impact, to see whether products are in stock and to quantify the costs of holding and buying the product.

The primary objects of material control are quantity and volume to be bought and shipped to ensure a balance between availability of goods and the current prices for them. Management of inventory should also concentrate on the decision-making since inventory is an entry point for growth for any retail organization.

Organizations should incorporate a computerized stock control system in order to monitor product cost efficiently and reliably, thus seeing all acceptable options regarding growing stock and proper time of purchases. The inventory management program could be also beneficially incorporated into other processes such as accounting, production and warehousing since a computerized inventory management program makes all these processes much easier.

\section{References}

Heese, H. S. (2015). Single versus multiple sourcing and the evolution of bargaining positions. Omega, 54: 125-133. 
Mbula, K.J., Memba, F., \& Njeru, A. (2016). Effect of Inventory Management on Financial Performance of Firms Funded by Government Venture Capital in Kenya. European Journal of Business and Management, 8(5).

Lundu, B. L., \& Shale, N. (2015). Effect of integrated financial management information system (IFMIS) implementation on supply chain management performance in the devolved government systems in Kenya: A case of Nairobi city county government. International Academic Journal of Procurement and Supply Chain Management, 1(5): 1-26.

Ogbo, A. I., \& Ukpere, W. I. (2014). The impact of effective inventory control management on organisational performance: A study of 7up bottling company Nile Mile Enugu, Nigeria. Mediterranean Journal of Social Sciences, 5(10): 109.

Patil, H., \& Divekar, B. R. (2014). Inventory Management Challenges for B2C E-commerce Retailers. Procedia Economics and Finance, 11: 561-571.

Ruth, K. (2012). Information Technology and procurement process in Kenya. Master Thesis, School Of Business, University Of Nairobi.

Thorsen, A., \& Yao, T. (2017). Robust inventory control under demand and lead time uncertainty. Annals of Operations Research, 257(1-2): 207-236.

Vipulesh, S. (2015). Impact of Inventory Management on the Financial Performance of the firm. IOSR Journal of Business and Management, 17(4): 01-12.

Paper submitted

Paper accepted for publishing

Paper published online
06 June 2021

21 August 2021

30 September 2021 